\title{
The Role of IL-17 Cytokines in Psoriasis
}

\author{
Megan Mosca (D) \\ Julie Hong \\ Edward Hadeler \\ Marwa Hakimi \\ Wilson Liao iD \\ Tina Bhutani
}

Psoriasis and Skin Treatment Center, Department of Dermatology, University of California San Francisco, San Francisco, CA, USA
Correspondence: Megan Mosca

Psoriasis and Skin Treatment Center, Department of Dermatology, University of California San Francisco, 515 Spruce Street, San Francisco, CA, 94118, USA

Emailmmosca@med.unr.edu

\begin{abstract}
Psoriasis is a chronic inflammatory skin condition associated with immune dysregulation. The immunologic cascade mediated by the interleukin (IL)-17 pathway plays a critically important role in the pathogenesis of psoriasis. The IL-17 effectors (IL17A, IL-17C, IL-17E, and IL17F) act on keratinocytes, endothelial cells, and immune cells to stimulate epidermal hyperplasia and the pro-inflammatory feed-forward cycle seen within plaque psoriasis. The IL-17 pathway is also hypothesized to modulate the inflammatory responses linking comorbid systemic diseases with psoriasis. Furthermore, the robust clinical response seen with current and emerging therapies targeting IL-17 emphasizes the importance of the IL-17 cytokines in the pathogenesis of psoriasis.
\end{abstract}

Keywords: IL-17, plaque psoriasis, pathogenesis, biologics, immune pathway

\section{Introduction}

Psoriasis is a chronic immune-mediated, inflammatory skin condition, which affects approximately 7.4 million adults in the United States. ${ }^{1}$ It is characterized by welldemarcated, erythematous, scaly plaques and involves increased keratinocyte proliferation and pro-inflammatory cytokines. ${ }^{2}$ While the pathogenesis is complex and not fully elucidated, psoriasis is thought to result from a combination of immunologic, genetic, and environmental factors. ${ }^{2}$ Upregulation and activation of immune pathways play a crucial role in the immunologic mechanism of psoriasis. The interleukin-23/ T helper 17 (IL-23/Th17) mediated activation of IL-17 is recognized as the dominant pathway and plays a critical role in the pathogenesis of psoriasis. ${ }^{3,4}$

The IL-17 signaling pathway and its products are key contributors to psoriatic inflammation. Given its pathogenic role, this pathway has become a therapeutic target for several psoriasis treatments. Currently, three biologic therapies targeting the IL-17 pathway are FDA approved for the treatment of moderate to severe plaque psoriasis: ixekizumab, secukinumab, and brodalumab. Additionally, current research is underway to evaluate the efficacy of two new biologic treatments, bimekizumab, an inhibitor of IL-17A and IL-17-F, and netakimab, an inhibitor of IL-17A. ${ }^{5,6}$ An update on the contribution of the IL-17 cytokines in psoriasis pathogenesis and its involvement in mediating comorbid conditions is discussed below. Additionally, we highlight the pertinent Phase III efficacy and safety data of IL-17 inhibitors, emphasizing recent studies and novel therapeutic agents.

\section{Biology of the IL-I 7 Family}

The IL-17 family consists of six isoforms (IL-17A-IL-17F). ${ }^{7}$ IL-17A and IL-17F are primarily involved in the pathogenesis of psoriasis, but IL-17C and IL-17E are also implicated in the disease state. Furthermore, the expression of these four 
cytokines is increased within psoriatic skin lesions, supporting their role in psoriasis. ${ }^{8-10}$ Protein levels of IL-17A, IL-17C, and IL-17F in lesional psoriatic skin are significantly increased by 6.7 -fold, 4.1 -fold, and 8 -fold, respectively, when compared to nonlesional skin. ${ }^{9}$

IL-17A and IL-17F share the most homologous structure, sharing approximately $50 \%$ of their sequence identity. ${ }^{11}$ IL-17A exists in two forms, as a homodimer and a heterodimer in combination with IL-17F (IL-17A/ IL17F). Additionally, IL-17A homodimer, IL-17F homodimer, and IL-17A/IL-17F heterodimer all bind to the same heterodimeric receptor, IL-17R, which is comprised of IL-17RA and IL-17RC. ${ }^{12}$ However, the IL-17A homodimer is the most biologically active isomer with downstream gene activation approximately 10-30 fold stronger when compared to activation by the IL-17F homodimer. ${ }^{12,13}$

\section{Role of the IL-I 7 Cytokines in Psoriasis}

Under physiologic conditions, the IL-17 pathway contributes to defenses against extracellular fungi and bacteria. In particular, IL-17A bridges the gap between the innate and adaptive immune systems. Through chemokine expression and gradients, IL-17A initiates immune responses at mucosal surfaces, resulting in the recruitment of neutrophils to the tissue. ${ }^{14}$ Neutrophils, in turn, secrete IL-17, which amplifies the response and leads to the recruitment of additional neutrophils. ${ }^{15}$

However, the IL-17 pathway also plays a significant role in the origin and the feed-forward inflammatory cycle of psoriasis. When an individual with a genetic predisposition experiences a trigger for psoriasis, the adaptive immune system initiates an immunologic cascade. ${ }^{2}$ Myeloid dendritic cells initiate the release of IL-12 and IL-23; however, the IL-23 pathway is believed to be the predominant pathway in psoriasis pathogenesis. ${ }^{2}$ IL-23 supports the survival, differentiation, and activation of Th17 cells, which secrete IL-17 cytokines. ${ }^{2,16}$ While Th17 cells were previously thought to be the primary source of IL-17, new research suggests that mast cells and neutrophils are the predominant cell type containing and releasing IL-17 in psoriatic skin. ${ }^{15}$ This subpopulation of neutrophils and mast cells release IL-17 through IL-23 activation, which may explain why therapies targeting IL23 are efficacious in psoriasis. ${ }^{17,18}$ Additional sources of IL-17 may include innate lymphoid cells, natural killer cells, and gamma-delta T-cells. ${ }^{16}$
Keratinocytes, endothelial cells, and immune cells are all downstream targets of IL-17 in the psoriasis pathway (Table 1). IL-17 acts directly on keratinocytes, resulting in keratinocyte proliferation and the production of psoriasisrelated cytokines, chemokines, and antimicrobial peptides. Factors released by the keratinocytes promote the positive feedback loop by stimulating the production of additional inflammatory cells and IL-17-producing cells. ${ }^{7}$ While IL$17 \mathrm{~A}$ and IL-17F act individually as pro-inflammatory mediators in the psoriasis cascade, in combination, they also work synergistically to promote increased inflammation. ${ }^{18}$ Neutralization of both cytokines demonstrated greater downregulation in inflammation in vitro than with IL-17A or IL-17F blockade alone. ${ }^{19}$ In addition, IL-17E amplifies the inflammatory feedback cycle through the upregulation of genes involved in chemotaxis, ultimately promoting innate cellular recruitment and activation. ${ }^{20}$ IL-17 also promotes procoagulant activity in endothelial cells and upregulates pro-inflammatory effects on macrophages and dendritic cells. ${ }^{13,21}$

In addition to this pathway, IL-17 acts synergistically with TNF- $\alpha$ to coregulate psoriasis-related cytokines and keratinocyte genes. ${ }^{22}$ Receptors for both TNF- $\alpha$ and IL-17 are expressed on keratinocytes. When the two receptors are stimulated simultaneously, the resulting levels of inflammatory cytokines are synergistically or additively upregulated. $^{22}$ This relationship is further supported by over $350 \mathrm{IL}-17 / \mathrm{TNF}-\alpha$ coregulated genes, many of which are highly expressed in psoriatic skin. ${ }^{22}$

\section{IL-I 7 and Psoriasis Comorbidities}

While psoriasis is highly associated with several comorbidities including cardiovascular disease, metabolic syndrome, psychological illness, inflammatory bowel disease, and obesity, the exact mechanism behind this relationship is unknown. ${ }^{23-27}$ Alterations and dysfunction of the immune system are proposed to be key mechanisms linking these disease states. Given the fundamental role that it plays in psoriatic disease, the IL-17 pathway is hypothesized to modulate the inflammatory responses seen in both primary psoriatic skin disease and comorbid systemic disease. Specifically, research suggests that IL-17 may play a pathogenic role in psoriasis-associated cardiovascular dysfunction, depressive disorder, and obesity.

Several studies support the role of IL-17 in psoriasis and vascular dysfunction. ${ }^{28}$ Studies of mice demonstrated that overexpression of IL-17A in keratinocytes resulted in psoriasis-like skin changes and increased downstream 
Table I IL-I7 Cytokine-Mediated Downstream Effects Involved in Plaque Psoriasis

\begin{tabular}{|c|c|c|c|c|c|c|}
\hline $\begin{array}{l}\text { IL-I7 } \\
\text { Isomer }\end{array}$ & $\begin{array}{l}\text { Relevant } \\
\text { Sources }\end{array}$ & Receptors & Targets & Effects & $\begin{array}{l}\text { Targeted } \\
\text { Therapy }\end{array}$ & Ref \\
\hline \multirow[t]{3}{*}{ IL-17 A } & \multirow[t]{3}{*}{$\begin{array}{l}\text { Th } 17 \text { cells } \\
\text { CD8+ T cells } \\
\text { Neutrophils } \\
\text { NK cells } \\
\text { NKT cells }\end{array}$} & \multirow[t]{3}{*}{$\begin{array}{l}\text { IL-I7RA } \\
\text { IL-I7RC }\end{array}$} & Keratinocytes & $\begin{array}{l}\text { Induces keratinocyte proliferation } \\
\text { Promotes production of psoriasis-related cytokines, } \\
\text { chemokines, inflammatory mediators, and } \\
\text { antimicrobial peptides (ie IL-6, IL-8, chemokine CC } \\
\text { motif ligand 20, granulocyte colony-stimulating factor, } \\
\text { and granulocyte-macrophage colony-stimulating } \\
\text { factor) }\end{array}$ & \multirow[t]{3}{*}{$\begin{array}{l}\text { Ixekizumab } \\
\text { Secukinumab } \\
\text { Bimekizumab } \\
\text { Netakimab } \\
\text { Brodalumab } \\
\text { (anti-IL } \\
\text { - I 7RA) }\end{array}$} & \multirow[t]{3}{*}[7,|8,21]{} \\
\hline & & & $\begin{array}{l}\text { Endothelial } \\
\text { cells }\end{array}$ & $\begin{array}{l}\text { Stimulates the release of IL-16, IL- } 8 \text {, tissue factor, and } \\
\text { intracellular adhesion molecule- } \mathrm{I} \rightarrow \text { procoagulant } \\
\text { activity and inflammation }\end{array}$ & & \\
\hline & & & $\begin{array}{l}\text { Macrophages } \\
\text { and dendritic } \\
\text { cells }\end{array}$ & $\begin{array}{l}\text { Stimulates the release of IL- } 16, \mathrm{IL}-8 \text {, tissue factor, and } \\
\text { intracellular adhesion molecule- } \mathrm{I} \rightarrow \text { procoagulant } \\
\text { activity and inflammation }\end{array}$ & & \\
\hline IL-17 C & Keratinocytes & $\begin{array}{l}\text { IL-I7RA } \\
\text { IL-I7RE }\end{array}$ & Keratinocytes & $\begin{array}{l}\text { Stimulates induction of human } \beta \text {-defensin } 2 \text { and } \\
\text { granulocyte colony-stimulating factor }\end{array}$ & $\begin{array}{l}\text { Brodalumab } \\
\text { (anti-IL } \\
\text {-I7RA) }\end{array}$ & {$[7,77]$} \\
\hline IL-I7 F & $\begin{array}{l}\text { ThI7 cells } \\
\text { CD8+ T cells } \\
\text { Neutrophils } \\
\text { NK cells } \\
\text { NKT cells }\end{array}$ & $\begin{array}{l}\text { IL-I7RA } \\
\text { IL-I7RC }\end{array}$ & Keratinocytes & $\begin{array}{l}\text { Induces keratinocyte proliferation } \\
\text { Promotes production of psoriasis-related cytokines, } \\
\text { chemokines, inflammatory mediators, and } \\
\text { antimicrobial peptides (ie IL-6, IL-8, chemokine CC } \\
\text { motif ligand 20, granulocyte colony-stimulating factor, } \\
\text { and granulocyte-macrophage colony-stimulating } \\
\text { factor) }\end{array}$ & $\begin{array}{l}\text { Bimekizumab } \\
\text { Brodalumab } \\
\text { (anti-IL } \\
\text {-I 7RA) }\end{array}$ & {$[7,|8,2|]$} \\
\hline IL-I7 E & $\begin{array}{l}\text { T cells } \\
\text { Intraepithelial } \\
\text { lymphocytes } \\
\text { Eosinophils } \\
\text { Basophils } \\
\text { Mast cells }\end{array}$ & $\begin{array}{l}\text { IL-I7RA } \\
\text { IL-I7RB }\end{array}$ & Keratinocytes & $\begin{array}{l}\text { Stimulates cellular proliferation, differentiation, and } \\
\text { migration of keratinocytes. } \\
\text { Also promotes release of pro-inflammatory cytokines/ } \\
\text { chemokines through STAT3 transcription factor }\end{array}$ & $\begin{array}{l}\text { Brodalumab } \\
\text { (anti-IL } \\
\text {-I7RA) }\end{array}$ & {$[7,20,78,79]$} \\
\hline
\end{tabular}

Abbreviations: IL, interleukin; IL-I7R, Interleukin- I7 recepto; NK cells, natural killer cells; NKT, natural killer T cells; ThI7 cells, T helper I7 cells; STAT3, signal transducer and activator of transcription 3; Ref, references.

vascular oxidative stress, endothelial dysfunction, and arterial hypertension. ${ }^{29,30}$ Research has also demonstrated that upstream components of the IL-17 pathway are associated with vascular dysfunction. Patients with carotid atherosclerosis were noted to have significantly increased plasma levels of IL-23 when compared to controls and increased levels of IL-23 and IL-23R were noted within atherosclerotic plaques. ${ }^{31}$ Furthermore, research demonstrates that serum IL-17 is increased threefold in hypertensive individuals and may mediate the critical hypertensive response to angiotensin II. ${ }^{32}$

Several studies with conflicting evidence suggest IL17 may be the immunologic link between psoriasis and depression. ${ }^{33}$ Elevated IL-17 levels are hypothesized to mediate depressive disorders through downstream activation of microglia and neuroinflammation with chemokines, cytokines, and neuroinflammatory mediators. ${ }^{33}$ The upregulation of IL-17 gene expression and increased serum levels in patients with major depressive disorders compared to healthy controls support IL-17 involvement in the disease process. ${ }^{34-37}$ In addition, mouse models of depressive brains demonstrated increased percentages of Th17 cells and increased levels of IL-17 interleukins. $^{38,39}$ However, the exact role of IL-17 in depression is unclear, and levels of IL-17 do not always correlate with disease. A meta-analysis of peripheral cytokine and chemokine alterations in depression did not find a significant difference between levels of IL-17 
in patients with major depressive disorder and healthy controls. $^{40}$ More research elucidating the connection between IL-17 and depression is needed.

In addition, IL-17 may mediate the feed-forward inflammatory cycle associated with obesity. ${ }^{33}$ Adipocytes and macrophages in visceral adipose tissue exacerbate the inflammatory state of psoriasis by promoting several proinflammatory cytokines, including IL-6, which mediates Th17 commitment by naïve T cells. ${ }^{41,42}$ IL-17 activates the positive feedback process by stimulating the production of IL-6. ${ }^{43}$ This process contributes to the elevated levels of plasma IL-17 observed in obese patients when compared to lean controls. ${ }^{44-46}$ Research hypothesizes that IL-17 ultimately mediates the link between obesity and psoriasis through maintaining inflammation in adipose tissue and stimulating lipolysis of adipocytes. ${ }^{47}$

\section{Targeted Therapies for the IL-I 7 Pathway}

Given the significant role of the IL-17 pathway in psoriasis, several targeted biologic therapies have emerged. Currently, three biologic therapies (ixekizumab, secukinumab, and brodalumab) are FDA approved for the treatment of plaque psoriasis and two novel biologics (bimekizumab and netakimab) are undergoing phase III clinical trial therapeutic evaluation. Network analyses with head-to-head comparisons demonstrate that agents targeting IL-17 and IL-23 tend to be more efficacious when compared to older drugs targeting TNF- $\alpha$ and IL-12/23 at several endpoints. ${ }^{48}$ The robust clinical response and fast-onset of action of anti-IL -17 agents in clinical trials highlight the fundamental role that IL-17 plays in psoriasis pathogenesis.

\section{Ixekizumab}

Ixekizumab, a humanized IgG4 monoclonal antibody against IL-17A, is approved by the FDA for the treatment of moderate to severe plaque in patients ages 6 and older. For adults, ixekizumab is administered with a $160 \mathrm{mg}$ loading dose at week 0 followed by $80 \mathrm{mg}$ at weeks 2,4 , $6,8,10$, and 12 , and $80 \mathrm{mg}$ every 4 weeks, thereafter. ${ }^{49}$ Dosing for pediatric patients is weight-based. Patients weighing less than $25 \mathrm{~kg}$ are recommended to receive a loading dose of $40 \mathrm{mg}$ at week 0 , followed by $20 \mathrm{mg}$ every 4 weeks. Patients weighing $25-50 \mathrm{~kg}$ receive a loading dose of $80 \mathrm{mg}$ at week 0 , followed by $40 \mathrm{mg}$ every 4 weeks. Patients who weigh greater than $50 \mathrm{~kg}$ are recommended to receive a loading dose of $160 \mathrm{mg}$ at week 0 , followed by $80 \mathrm{mg}$ every 4 weeks.

The efficacy and safety of ixekizumab have been evaluated in three randomized, double-blind, placebocontrolled phase III trials: UNCOVER-1, UNCOVER-2, and UNCOVER-3. ${ }^{50,51}$ In UNCOVER-1, two dosing regimens of ixekizumab ( $80 \mathrm{mg}$ every 2 weeks versus every 4 weeks) was compared to placebo and in UNCOVER-2/3 etanercept was used as an active comparator. Ixekizumab was superior to placebo and etanercept in terms of the Psoriasis Area and Severity Index (PASI) 75 at week 12 in all three studies. In UNCOVER-1, PASI 75 was achieved by $89.1 \%$ of patients on ixekizumab $80 \mathrm{mg}$ every 2 weeks, $82.6 \%$ of patients on ixekizumab $80 \mathrm{mg}$ every 4 weeks, and $3.9 \%$ of patients on placebo $(\mathrm{p}<0.001) .{ }^{50}$ In UNCOVER-2, PASI 75 was achieved by $89.7 \%, 77.5 \%, 41.6 \%$, and $2.4 \%$ of patients with ixekizumab $80 \mathrm{mg}$ every 2 weeks, ixekizumab $80 \mathrm{mg}$ every 4 weeks, etanercept, and placebo, respectively $(\mathrm{p}<0.0001)$. UNCOVER-3 supported these findings with 87.3\%, $84.2 \%, 53.4 \%$, and $7.3 \%$ of patients achieving PASI 75 with ixekizumab $80 \mathrm{mg}$ every 2 weeks, ixekizumab $80 \mathrm{mg}$ every 4 weeks, etanercept, and placebo, respectively $(\mathrm{p}<0.0001){ }^{51}$ A long-term extension of UNCOVER-3 demonstrated that ixekizumab maintained high levels of efficacy through 4 years of treatment (PASI 75: $82.8 \%$ of patients, PASI $90: 66.4 \%$ of patients, and PASI 100: $48.3 \%$ of patients). ${ }^{52}$

Ixekizumab demonstrated superiority and noninferiority when studied head-to-head against ustekinumab and guselkumab, respectively. The randomized, double-blind clinical trial, IXORA-S, demonstrated that ixekizumab was superior to ustekinumab at week 12 in PASI 75 (88.2\% vs $68.7 \%$ of patients, $\mathrm{p}<0.001)$, PASI $90(72.8 \%$ vs $42.2 \%$ of patients, $\mathrm{p}<0.001)$, and PASI 100 (36.0\% vs $14.5 \%$ of patients, $\mathrm{p}<0.01){ }^{53}$ The clinical superiority that ixekizumab demonstrated at week 12 was maintained through week $52 .{ }^{54}$ In the randomized, double-blind clinical trial, IXORA-R, ixekizumab led to higher proportions of patients achieving PASI 100 when compared to guselkumab at week 12 (41\% vs $25 \%$ of patients, respectively, $\mathrm{p}<0.01$ ); however, by week 24 there was no statistically significant difference in PASI 100 between ixekizumab and guselkumab treatment $(50 \%$ vs $52 \%$ of patients, respectively, $\mathrm{p}=0.41)^{55,56}$

In clinical trials, the most common adverse events for ixekizumab were nasopharyngitis, upper respiratory tract infection, and injection-site reactions. Ixekizumab 
treatment was associated with more events of Candida infections and neutropenia than etanercept or placebo. ${ }^{50,51}$ Injection site reactions were also more common with ixekizumab when compared to guselkumab. ${ }^{56}$

\section{Secukinumab}

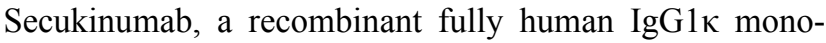
clonal antibody against IL-17A, was approved by the FDA for the treatment of moderate to severe plaque psoriasis in patients ages 6 years and older. ${ }^{57}$ The dosing schedule of secukinumab for adults is $300 \mathrm{mg}$ at weeks $0,1,2,3$, and 4 followed by $300 \mathrm{mg}$ every 4 weeks. The pediatric dosing is based on weight. Pediatric patients less than $50 \mathrm{~kg}$ are recommended $75 \mathrm{mg}$ at weeks $0,1,2,3$, and 4 , followed by every 4 weeks, thereafter. Pediatric patients greater than or equal to $50 \mathrm{~kg}$ are recommended $150 \mathrm{mg}$ at weeks 0,1 , 2,3 , and 4 , followed by every 4 weeks.

Secukinumab has been evaluated in two, double-blind, placebo-controlled phase III clinical trials, ERASURE and FIXTURE. $^{58}$ In the ERASURE study, secukinumab $300 \mathrm{mg}$ and $150 \mathrm{mg}$ were compared to placebo, and in the FIXTURE study, etanercept was used as an active comparator. Secukinumab was superior to placebo and etanercept in terms of PASI 75 at week 12 in both studies. In ERASURE, PASI 75 was achieved by $81.6 \%$ of patients with $300 \mathrm{mg}$ of secukinumab, $71.6 \%$ of patients with $150 \mathrm{mg}$ of secukinumab, and $4.5 \%$ of patients with placebo at week $12(p<0.001)$. In FIXTURE, PASI 75 was achieved by $77.1 \%$ of patients with $300 \mathrm{mg}$ of secukinumab, $67.0 \%$ of patients with $150 \mathrm{mg}$ of secukinumab, $44.0 \%$ of patients with etanercept, and $4.9 \%$ of patients with placebo $(\mathrm{p}<0.001)$.

The administration of secukinumab via pre-filled syringes and autoinjectors was also evaluated in FEATURE and JUNCTURE, respectively. ${ }^{59,60}$ Subject-rated acceptability of both methods of administration was high throughout the 12 weeks. In both studies, secukinumab was superior to placebo in PASI 75 results at week 12 $(\mathrm{p}<0.0001)$.

CLEAR and CLARITY, two head-to-head phase III clinical trials, demonstrated the superiority of secukinumab when compared to ustekinumab. ${ }^{61-64}$ Secukinumab was superior to ustekinumab as measured by PASI 90 (CLEAR: $79.0 \%$ vs $57.6 \%$ of patients, CLARITY: $76.6 \%$ vs 54.2 of patients, respectively, $\mathrm{p}<0.0001)$ and PASI 100 (CLEAR: $44.3 \%$ vs $28.4 \%$ of patients, CLARITY: $45.3 \%$ vs $26.7 \%$ of patients, $\mathrm{p}<0.0001$ ) at week 16 , which was maintained through week 52. Secukinumab has also been compared head-to-head with guselkumab in the randomized, double-blind, phase III clinical trial, ECLIPSE. ${ }^{65}$ Guselkumab was superior to secukinumab as measured by PASI 90 at week $48(84.0 \%$ vs $70.0 \%$ of patients, respectively $\mathrm{p}<0.0001)$. However, no significant difference between guselkumab and secukinumab treatment was established for PASI 75 response at weeks 12 or 48 (85\% and $80 \%$ of patients, responses at weeks 12 and 48 , respectively, $\mathrm{p}<0.0616$ ). Secukinumab was also compared to risankizumab in the clinical trial, IMMerge, but it resulted in less clinical clearance than its comparator. ${ }^{66} \mathrm{At}$ week 16, no statistical difference was noted in PASI 90 response between risankizumab and secukinumab $(73.8 \%$ vs $65.6 \%$ of patients, respectively); however, risankizumab led to a superior PASI 90 response by week 52 (86.6\% vs $57.1 \%$ of patients, respectively, $\mathrm{p}<0.001$ )

A long-term extension study, SCULPTURE, showed that secukinumab maintains high efficacy and a good safety profile through five years of treatment. ${ }^{67}$ A comparison of secukinumab efficacy responses demonstrates that PASI 75/90/100 at year $1(88.9 \%, 68.5 \%$, and $43.8 \%$ of patients, respectively) were maintained through year $5(88.5 \%, 66.4 \%$, and $41 \%$ of patients).

The most common adverse events during phase III clinical trials of secukinumab included nasopharyngitis, headache, and diarrhea. ${ }^{58}$ Overall rates of infection with secukinumab were higher than placebo but were similar to rates with etanercept and ustekinumab treatment. Candida infections also occurred more frequently with secukinumab treatment compared to etanercept treatment. ${ }^{58,64}$

\section{Brodalumab}

Brodalumab, a human monoclonal IL-17 receptor antibody (RA) antibody, was approved by the FDA for the treatment of adults with moderate to severe plaque psoriasis. ${ }^{68}$ The recommended dosing schedule of brodalumab for adults is $210 \mathrm{mg}$ at weeks 0,1 , and 2 , followed by $210 \mathrm{mg}$ every 2 weeks.

Brodalumab was evaluated in three randomized double-blind, phase III clinical trials, AMAGINE-1, AMAGINE-2, and AMAGINE-3. ${ }^{69,70}$ Brodalumab (140 and $210 \mathrm{mg}$ ) was compared to placebo in AMAGINE-1 and in AMAGINE-2/3 ustekinumab was added as an active comparator. In AMAGINE-1, a significantly greater proportion of patients treated with brodalumab $210 \mathrm{mg}$ and $140 \mathrm{mg}$ achieved PASI 75 (83.3\% and $60.3 \%$ vs $2.7 \%$ of patients, respectively, $\mathrm{p}<0.001)$ PASI 90 (70\% and $43 \%$ vs $1 \%$ of patients, $\mathrm{p}<0.001)$, and PASI 100 (42\% and $23 \%$ vs 
$1 \%$ of patients, $\mathrm{p}<0.001)$ compared to placebo at week $12 .^{69}$ Brodalumab $210 \mathrm{mg}$ also resulted in significantly higher PASI 100 responses than ustekinumab and placebo in both AMAGINE-2 ( $44 \%$ vs $22 \%$ vs $1 \%$ of patients, respectively, $\mathrm{p}<0.001)$ and AMAGINE-3 (37\% vs $19 \%$ vs $0.3 \%$ of patients, $\mathrm{p}<0.001$ ) at week 12 . Treatment with brodalumab $210 \mathrm{mg}$ showed robust efficacy with maintained skin clearance through 120 weeks in the long-term evaluation of AMAGINE-2. ${ }^{71}$

The most common adverse event noted in clinical trials were respiratory tract infections, headaches, and arthralgias. ${ }^{69,70}$ Candida infections were more frequently associated with brodalumab than with ustekinumab or placebo. ${ }^{70}$ Four completed suicides were reported across Phase II, Phase III, and long-term extension trials leading to a black box warning for suicidal ideation and behavior. Although, followup evaluation has suggested no causal relationship between brodalumab treatment and suicidal behavior. ${ }^{72}$

\section{Bimekizumab}

Bimekizumab is an investigational monoclonal humanized IgG1 antibody that simultaneously inhibits both IL-17A and IL-17F. Four phase III clinical trials, BE VIVID, BE READY, BE SURE, and BE RADIANT, have demonstrated significant clinical improvements and a good safety profile associated with bimekizumab, but it is not currently approved by the FDA. ${ }^{73-76}$ A dosing schedule has not been provided by the FDA; however, clinical trials have demonstrated equivalent efficacy between bimekizumab $320 \mathrm{mg}$ every 4 weeks and every 8 weeks.

BE READY, a multicenter, double-blind placebocontrolled phase III clinical trial, demonstrated that bimekizumab was significantly more effective than placebo and maintained clinical response through week $56 .{ }^{73}$ Patients were randomized to receive either bimekizumab $320 \mathrm{mg}$ every 4 weeks or placebo. At week 16, patients who achieved PASI 90 with bimekizumab were re-randomized to bimekizumab 320mg every 4 weeks or every 8 weeks, or placebo. Patients treated with bimekizumab were more likely to achieve PASI 90 at week 16 compared to placebo (91.0\% vs $1.0 \%$ of patients, respectively, $\mathrm{p}<0.0001)$. By week 16, complete clearance (PASI 100) was also achieved by $68.2 \%$ of patients treated with bimekizumab compared to $1.2 \%$ of patients with placebo $(\mathrm{p}<0.0001)$. PASI 90 was also maintained through week 56 by $87.0 \%$ of patients randomized to bimekizumab $320 \mathrm{mg}$ every 4 weeks and $91.0 \%$ of patients randomized to bimekizumab $320 \mathrm{mg}$ every 8 weeks (vs placebo: $16.0 \%$ of patients, $\mathrm{p}<0.0001$ ).
Bimekizumab demonstrated superiority when compared to ustekinumab, adalimumab, and secukinumab in the active comparator, randomized, double-blind phase III clinical trials: BE VIVID, BE SURE, and BE RADIANT, respectively. ${ }^{74-76}$ In the clinical trial, BE VIVID, patients were randomized to receive either bimekizumab $320 \mathrm{mg}$ every 4 weeks, ustekinumab, or placebo. At week 16, bimekizumab was superior to ustekinumab and placebo in PASI 90 response $(85.0 \%$ vs $50.0 \%$ vs $5.0 \%$ of patients, respectively, $\mathrm{p}<0.0001) .{ }^{74}$ PASI 90 results were also sustained through week 52 (bimekizumab: $82.0 \%$ of patients vs ustekinumab: $56.0 \%$ of patients, $\mathrm{p}<0.0001$ ). Participants in the BE SURE phase III clinical trial were randomized to receive bimekizumab $320 \mathrm{mg}$ every 4 weeks for 56 weeks, bimekizumab every 4 weeks for 16 weeks, followed by every 8 weeks for 56 weeks, or adalimumab for 24 weeks followed by bimekizumab every 4 weeks. ${ }^{75}$ By week 16 , bimekizumab was superior to adalimumab in PASI 90 $(86.2 \%$ vs $47.2 \%$ of patients, $\mathrm{p}<0.001)$ and PASI 100 (60.8 vs $23.9 \%$ of patients, $(p<0.001)$. In BE RADIANT, patients were randomized to either receive bimekizumab $320 \mathrm{mg}$ every 4 weeks or secukinumab. ${ }^{76}$ At week 16 and week 48 , bimekizumab resulted in a significantly greater percentage of patients achieving PASI 100 compared to secukinumab (week 16: $61.7 \%$ vs $48.9 \%$ of patients, week 48: $67.0 \%$ vs $46.2 \%$ of patients, respectively, $\mathrm{p}<0.001$ ).

The incidence of adverse events was similar between treatment groups in the bimekizumab clinical trials. Across all phase III clinical trials, nasopharyngitis, oral candidiasis, and upper respiratory tract infections were the most common adverse events in the bimekizumab treatment groups. Bimekizumab was associated with greater rates of oral candidiasis compared to secukinumab and greater rates of oral candidiasis and diarrhea compared to adalimumab. ${ }^{75,76}$

\section{Netakimab}

Netakimab is an investigational humanized monoclonal IgG1 antibody that inhibits IL-17A. ${ }^{6}$ It is currently being evaluated for the treatment of plaque psoriasis. While the FDA has not provided dosing, clinical trials have demonstrated good efficacy with netakimab $120 \mathrm{mg}$ every 4 weeks.

A recent phase III randomized double-blind placebocontrolled clinical trial, PLANETA, demonstrated that netakimab was superior to placebo for the treatment of moderate-to-severe plaque. ${ }^{6}$ Patients were randomized to receive netakimab 120mg every 2 weeks, netakimab $120 \mathrm{mg}$ every 4 weeks, or placebo. Following week 12, all patients continued on netakimab every 4 weeks through week 54 . 
A significantly greater proportion of patients treated with netakimab every 2 and 4 weeks achieved PASI 75 at week 12 compared to placebo $(77.7 \%$ and $83.3 \%$ vs $0.0 \%$ of patients, respectively, $\mathrm{p}<0.0001)$. By week 52 , both the group who switched to every 4 weeks dosing and continued on every 4 weeks dosing maintained a PASI 75 response (94.1\% and $92.9 \%$ of patients, respectively).

Rates of treatment-related adverse events were similar between all treatment groups. The most common adverse events were hypercholesterolemia, neutropenia, and upper respiratory tract infections.

\section{Conclusions}

The IL-17 axis is a key pro-inflammatory mediator involved in immune dysregulation. Recent research details the widespread pro-inflammatory impact of IL-17 cytokines, which further illuminates its role in psoriasis pathogenesis and psoriasis comorbidities. The significant cutaneous clearance seen by psoriasis patients treated with established and novel IL-17 inhibitors emphasizes the importance of the IL-17 pathway in the immunologic origins of psoriasis. Furthermore, it is interesting to note the synergistic and cumulative effects of the IL-17 cytokines in psoriasis pathogenesis, which supports the thought process behind therapies that inhibit multiple IL-17 isoforms. Brodalumab, a human monoclonal IL-17 RA antibody, is currently the only FDAapproved therapy that inhibits multiple IL-17 cytokines; however, bimekizumab, a monoclonal humanized IgG1 antibody against IL-17A and IL-17F, is also under investigation. While it is difficult to compare clinical response to therapies without head-to-head studies, PASI scores tended to be higher in bimekizumab treated patients. The increased efficacy seen with dual inhibition therapy is one of the hypothesized benefits behind neutralizing multiple IL-17 cytokines for the treatment of plaque psoriasis. In addition, future research should explore the potential benefits of directed therapies against IL-17C and IL-17E, given their role in amplifying the inflammatory feedback loop and innate immune cell recruitment. Overall, future studies may focus on the impact of IL-17 cytokines on psoriatic comorbidities, the psoriasis inflammatory cascade, and responses to targeted therapies.

\section{Compliance with Ethics Guidelines}

This article is based on previously conducted studies and does not contain any new studies with human participants or animals performed by any of the authors.

\section{Acknowledgments}

This paper has not been previously published or posted and is not under consideration elsewhere.

\section{Funding}

No funding or sponsorship was received for this study or publication of this article.

\section{Disclosure}

Dr. Tina Bhutani has received research funding from Abbvie, Celgene, Galderma, Janssen, Pfizer, Regeneron, and Sun. She has served as an advisor for Abbvie, Boehringer-Ingelheim, Bristol Myers Squibb, Pfizer, Leo, Lilly, UCB, and Novartis. Dr. Wilson Liao has received research grant funding from Abbvie, Amgen, Janssen, Leo, Novartis, Pfizer, Regeneron, and TRex Bio. Megan Mosca, Julie Hong, Edward Hadeler, and Dr. Marwa Hakimi have nothing to disclose.

\section{References}

1. Rachakonda TD, Schupp CW, Armstrong AW. Psoriasis prevalence among adults in the United States. $J$ Am Acad Dermatol. 2014;70 (3):512-516. doi:10.1016/j.jaad.2013.11.013

2. Armstrong AW, Read C. Pathophysiology, clinical presentation, and treatment of psoriasis: a Review. JAMA. 2020;323(19):1945-1960. doi:10.1001/jama.2020.4006

3. Nestle FO, Kaplan DH, Barker J. Psoriasis. N Engl J Med. 2009;361 (17):496-509. doi:10.1056/NEJMra0804595

4. Aggarwal S, Ghilardi N, Xie M-H, de Sauvage FJ, Gurney AL. Interleukin-23 promotes a distinct $\mathrm{CD} 4 \mathrm{~T}$ cell activation state characterized by the production of interleukin-17. J Biol Chem. 2003;278 (3):1910-1914. doi:10.1074/jbc.M207577200

5. Gotesman RD, Vender R. Bimekizumab for moderate-to-severe plaque psoriasis. Skin Therapy Lett. 2021;26(3):1-4.

6. Puig L, Bakulev AL, Kokhan MM, et al. Efficacy and safety of netakimab, A Novel Anti-IL-17 monoclonal antibody, in patients with moderate to severe plaque psoriasis. Results of A 54-Week Randomized Double-Blind Placebo-Controlled PLANETA Clinical Trial. Dermatol Ther (Heidelb). 2021;11(4):1319-1332. doi:10.1007/s13555-021-00554-4

7. Martin DA, Towne JE, Kricorian G, et al. The emerging role of interleukin-17 in the pathogenesis of psoriasis: preclinical and clinical findings. $J$ Invest Dermatol. 2013;133(1):17-26. doi:10.1038/ jid.2012.194

8. Johnston A, Fritz Y, Dawes SM, et al. Keratinocyte overexpression of IL-17C promotes psoriasiform skin inflammation. J Immunol. 2013;190(5):2252-2262. doi:10.4049/jimmunol.1201505

9. Johansen C, Usher PA, Kjellerup RB, Lundsgaard D, Iversen L, Kragballe K. Characterization of the interleukin-17 isoforms and receptors in lesional psoriatic skin. $B r J$ Dermatol. 2009;160 (2):319-324. doi:10.1111/j.1365-2133.2008.08902.x

10. Senra L, Stalder R, Alvarez Martinez D, Chizzolini C, Boehncke W-H, Brembilla NC. Keratinocyte-derived IL-17E contributes to inflammation in psoriasis. J Invest Dermatol. 2016;136 (10):1970-1980. doi:10.1016/j.jid.2016.06.009

11. Zhang X, Angkasekwinai P, Dong C, Tang H. Structure and function of interleukin-17 family cytokines. Protein Cell. 2011;2(1):26-40. doi:10.1007/s13238-011-1006-5

12. Gaffen SL. Structure and signalling in the IL-17 receptor superfamily. Nat Rev Immunol. 2009;9(8):556. doi:10.1038/nri2586 
13. Chiricozzi A, Krueger JG. IL-17 targeted therapies for psoriasis. Expert Opin Investig Drugs. 2013;22(8):993-1005. doi:10.1517/ 13543784.2013.806483

14. Bettelli E, Korn T, Oukka M, Kuchroo VK. Induction and effector functions of T(H)17 cells. Nature. 2008;453(7198):1051-1057. doi: 10.1038 /nature 07036

15. Lin AM, Rubin CJ, Khandpur R, et al. Mast cells and neutrophils release IL-17 through extracellular trap formation in psoriasis. J Immunol. 2011;187(1):490-500. doi:10.4049/jimmunol.1100123

16. Alwan W, Nestle FO. Pathogenesis and treatment of psoriasis: exploiting pathophysiological pathways for precision medicine. Clin Exp Rheumatol. 2015;33(5 Suppl 93):S2-6.

17. Li Y, Zhu L, Chu Z, et al. Characterization and biological significance of IL-23-induced neutrophil polarization. Cell Mol Immunol. 2018;15 (5):518-530. doi:10.1038/cmi.2017.39

18. Brembilla NC, Senra L, Boehncke W-H. The IL-17 family of cytokines in psoriasis: IL-17A and beyond. Front Immunol. 2018;9:1682. doi:10.3389/fimmu.2018.01682

19. Glatt S, Baeten D, Baker T, et al. Dual IL-17A and IL-17F neutralisation by bimekizumab in psoriatic arthritis: evidence from preclinical experiments and a randomised placebo-controlled clinical trial that IL-17F contributes to human chronic tissue inflammation. Ann Rheum Dis. 2018;77(4):523-532. doi:10.1136/annrheumdis-2017-212127

20. Senra L, Mylonas A, Kavanagh RD, et al. IL-17E (IL-25) enhances innate immune responses during skin inflammation. $J$ Invest Dermatol. 2019;139(8):1732-1742.e17. doi:10.1016/j.jid.2019.01. 021

21. Miossec P, Kolls JK. Targeting IL-17 and TH17 cells in chronic inflammation. Nat Rev Drug Discov. 2012;11(10):763-776. doi:10. 1038/nrd3794

22. Chiricozzi A, Guttman-Yassky E, Suárez-Fariñas M, et al. Integrative responses to IL-17 and TNF- $\alpha$ in human keratinocytes account for key inflammatory pathogenic circuits in psoriasis. J Invest Dermatol. 2011;131(3):677-687. doi:10.1038/jid.2010.340

23. Armstrong AW, Harskamp CT, Armstrong EJ. Psoriasis and metabolic syndrome: a systematic review and meta-analysis of observational studies. J Am Acad Dermatol. 2013;68(4):654-662. doi:10. 1016/j.jaad.2012.08.015

24. Mansouri B, Kivelevitch D, Natarajan B, et al. Comparison of coronary artery calcium scores between patients with psoriasis and type 2 diabetes. JAMA Dermatol. 2016;152(11):1244-1253. doi:10.1001/ jamadermatol.2016.2907

25. Dowlatshahi EA, Wakkee M, Arends LR, Nijsten T. The prevalence and odds of depressive symptoms and clinical depression in psoriasis patients: a systematic review and meta-analysis. J Invest Dermatol. 2014;134(6):1542-1551. doi:10.1038/jid.2013.508

26. Eppinga H, Poortinga S, Thio HB, et al. Prevalence and phenotype of concurrent psoriasis and inflammatory bowel disease. Inflamm Bowel Dis. 2017;23(10):1783-1789. doi:10.1097/MIB.0000000000 001169

27. Schwarz PEH, Pinter A, Melzer N, Barteczek P, Reinhardt M. ERAPSO: revealing the high burden of obesity in german psoriasis patients. Dermatol Ther (Heidelb). 2019;9(3):579-587. doi:10.1007/ s13555-019-0314-1

28. Egeberg A, Gisondi P, Carrascosa JM, Warren RB, Mrowietz U. The role of the interleukin-23/Th17 pathway in cardiometabolic comorbidity associated with psoriasis. J Eur Acad Dermatol Venereol. 2020;34(8):1695-1706. doi:10.1111/jdv.16273

29. Karbach S, Croxford AL, Oelze M, et al. Interleukin 17 drives vascular inflammation, endothelial dysfunction, and arterial hypertension in psoriasis-like skin disease. Arterioscler Thromb Vasc Biol. 2014;34(12):2658-2668. doi:10.1161/ATVBAHA.114.304108

30. Schüler R, Brand A, Klebow S, et al. Antagonization of IL-17A attenuates skin inflammation and vascular dysfunction in mouse models of psoriasis. J Invest Dermatol. 2019;139(3):638-647. doi:10.1016/j.jid.2018.09.021
31. Abbas A, Gregersen I, Holm S, et al. Interleukin 23 levels are increased in carotid atherosclerosis: possible role for the interleukin 23/interleukin 17 axis. Stroke. 2015;46(3):793-799. doi:10.1161/ STROKEAHA.114.006516

32. Madhur MS, Lob HE, McCann LA, et al. Interleukin 17 promotes angiotensin II-induced hypertension and vascular dysfunction. Hypertension. 2010;55(2):500. doi:10.1161/HYPERTENSIONAHA. 109.145094

33. Zafiriou E, Daponte AI, Siokas V, Tsigalou C, Dardiotis E, Bogdanos DP. Depression and obesity in patients with psoriasis and psoriatic arthritis: is IL-17-mediated immune dysregulation the connecting link? Front Immunol. 2021;12:699848. doi:10.3389/ fimmu.2021.699848

34. Davami MH, Baharlou R, Ahmadi Vasmehjani A, et al. Elevated IL17 and TGF- $\beta$ serum levels: a positive correlation between T-helper 17 cell-related pro-inflammatory responses with major depressive disorder. Basic Clin Neurosci. 2016;7(2):137-142. doi:10.15412/J. BCN.03070207

35. Gałecka M, Bliźniewska-Kowalska K, Orzechowska A, et al. Inflammatory versus anti-inflammatory profiles in major depressive disorders-the role of IL-17, IL-21, IL-23, IL-35 and Foxp3. J Pers Med. 2021;11(2):66. doi:10.3390/jpm11020066

36. Chen Y, Jiang T, Chen P, et al. Emerging tendency towards autoimmune process in major depressive patients: a novel insight from Th17 cells. Psychiatry Res. 2011;188(2):224-230. doi:10.1016/j. psychres.2010.10.029

37. Alvarez-Mon MA, Gómez-Lahoz AM, Orozco A, et al. Expansion of CD4 T lymphocytes expressing interleukin 17 and tumor necrosis factor in patients with major depressive disorder. J Pers Med. 2021;11(3):220. doi:10.3390/jpm11030220

38. Beurel E, Harrington LE, Jope RS. Inflammatory T helper 17 cells promote depression-like behavior in mice. Biol Psychiatry. 2013;73 (7):622-630. doi:10.1016/j.biopsych.2012.09.021

39. Kim J, Suh Y-H, Chang K-A. Interleukin-17 induced by cumulative mild stress promoted depression-like behaviors in young adult mice. Mol Brain. 2021;14(1):11. doi:10.1186/s13041-020-00726-x

40. Köhler CA, Freitas TH, Maes M, et al. Peripheral cytokine and chemokine alterations in depression: a meta-analysis of 82 studies. Acta Psychiatr Scand. 2017;135(5):373-387. doi:10.1111/acps.12698

41. Wueest S, Konrad D. The role of adipocyte-specific IL-6-type cytokine signaling in FFA and leptin release. Adipocyte. 2018;7 (3):226-228. doi:10.1080/21623945.2018.1493901

42. Harbour SN, DiToro DF, Witte SJ, et al. TH17 cells require ongoing classic IL-6 receptor signaling to retain transcriptional and functional identity. Sci Immunol. 2020;5:49. doi:10.1126/sciimmunol.aaw2262

43. Owczarczyk-Saczonek A, Purzycka-Bohdan D, Nedoszytko B, et al. Pathogenesis of psoriasis in the "omic" era. Part III. Metabolic disorders, metabolomics, nutrigenomics in psoriasis. Postepy Dermatol Alergol. 2020;37(4):452-467. doi:10.5114/ada.2020.98284

44. Sumarac-Dumanovic M, Stevanovic D, Ljubic A, et al. Increased activity of interleukin-23/interleukin-17 proinflammatory axis in obese women. Int J Obes (Lond). 2009;33(1):151-156. doi:10.1038/ ijo.2008.216

45. Elisia I, Lam V, Cho B, et al. Exploratory examination of inflammation state, immune response and blood cell composition in a human obese cohort to identify potential markers predicting cancer risk. PLoS One. 2020;15(2):e0228633. doi:10.1371/journal.pone.0228633

46. Pirowska M, Obtułowicz A, Lipko-Godlewska S, Goździalska A, Podolec K, Wojas-Pelc A. The level of proinflammatory cytokines: interleukins 12, 23, 17 and tumor necrosis factor $\alpha$ in patients with metabolic syndrome accompanying severe psoriasis and psoriatic arthritis. Postepy Dermatol Alergol. 2018;35(4):360-366. doi:10.5114/ada.2018.77665

47. Owczarczyk-Saczonek A, Placek W. Interleukin-17 as a factor linking the pathogenesis of psoriasis with metabolic disorders. Int J Dermatol. 2017;56(3):260-268. doi:10.1111/ijd.13420 
48. Sbidian E, Chaimani A, Garcia-Doval I, et al. Systemic pharmacological treatments for chronic plaque psoriasis: a network meta-analysis. Cochrane Database Syst Rev. 2021;4:CD011535. doi:10.1002/14651858.CD011535.pub4

49. Highlights of prescribing information: Taltz. March 2021. Available from: https://uspl.lilly.com/taltz/taltz.html\#pi. Accessed June 8, 2021.

50. Gordon KB, Blauvelt A, Papp KA, et al. Phase 3 trials of ixekizumab in moderate-to-severe plaque psoriasis. $N$ Engl $J$ Med. 2016;375 (4):345-356. doi:10.1056/NEJMoa1512711

51. Griffiths CEM, Reich K, Lebwohl M, et al. Comparison of ixekizumab with etanercept or placebo in moderate-to-severe psoriasis (UNCOVER-2 and UNCOVER-3): results from two phase 3 randomised trials. Lancet. 2015;386(9993):541-551. doi:10.1016/S01406736(15)60125-8

52. Lebwohl MG, Gordon KB, Gallo G, Zhang L, Paul C. Ixekizumab sustains high level of efficacy and favourable safety profile over 4 years in patients with moderate psoriasis: results from UNCOVER-3 study. J Eur Acad Dermatol Venereol. 2020;34(2):301-309. doi:10.11 $11 / j d v .15921$

53. Reich K, Pinter A, Lacour JP, et al. Comparison of ixekizumab with ustekinumab in moderate-to-severe psoriasis: 24-week results from IXORA-S, a phase III study. Br J Dermatol. 2017;177(4):1014-1023. doi: $10.1111 /$ bjd. 15666

54. Paul C, Griffiths CEM, van de Kerkhof PCM, et al. Ixekizumab provides superior efficacy compared with ustekinumab over 52 weeks of treatment: results from IXORA-S, a phase 3 study. $J \mathrm{Am}$ Acad Dermatol. 2019;80(1):70-79.e3. doi:10.1016/j.jaad.2018.06. 039

55. Blauvelt A, Papp K, Gottlieb A, et al. A head-to-head comparison of ixekizumab vs. guselkumab in patients with moderate-to-severe plaque psoriasis: 12-week efficacy, safety and speed of response from a randomized, double-blinded trial. $B r J$ Dermatol. 2020;182 (6):1348-1358. doi:10.1111/bjd.18851

56. Blauvelt A, Leonardi C, Elewski B, et al. A head-to-head comparison of ixekizumab vs. guselkumab in patients with moderate-to-severe plaque psoriasis: 24-week efficacy and safety results from a randomized, double-blinded trial. $B r \quad J$ Dermatol. 2021;184 (6):1047-1058. doi:10.1111/bjd.19509

57. Highlights of prescribing information: Cosentyx; May, 2021. Available from: https://www.novartis.us/sites/www.novartis.us/files/ cosentyx.pdf. Accessed October 23, 2021.

58. Langley RG, Elewski BE, Lebwohl M, et al. Secukinumab in plaque psoriasis-results of two phase 3 trials. $N$ Engl J Med. 2014;371 (4):326-338. doi:10.1056/NEJMoa1314258

59. Blauvelt A, Prinz JC, Gottlieb AB, et al. Secukinumab administration by pre-filled syringe: efficacy, safety and usability results from a randomized controlled trial in psoriasis (FEATURE). $\mathrm{Br}$ J Dermatol. 2015;172(2):484-493. doi:10.1111/bjd.13348

60. Paul C, Lacour J-P, Tedremets L, et al. Efficacy, safety and usability of secukinumab administration by autoinjector/pen in psoriasis: a randomized, controlled trial (JUNCTURE). J Eur Acad Dermatol Venereol. 2015;29(6):1082-1090. doi:10.1111/jdv.12751

61. Thaçi D, Blauvelt A, Reich K, et al. Secukinumab is superior to ustekinumab in clearing skin of subjects with moderate to severe plaque psoriasis: CLEAR, a randomized controlled trial. $\mathrm{J} \mathrm{Am}$ Acad Dermatol. 2015;73(3):400-409. doi:10.1016/j. jaad.2015.05.013

62. Blauvelt A, Reich K, Tsai T-F, et al. Secukinumab is superior to ustekinumab in clearing skin of subjects with moderate-to-severe plaque psoriasis up to 1 year: results from the CLEAR study. $\mathrm{J} \mathrm{Am}$ Acad Dermatol. 2017;76(1):60-69.e9. doi:10.1016/j.jaad.2016.08. 008

63. Bagel J, Nia J, Hashim PW, et al. Secukinumab is superior to ustekinumab in clearing skin in patients with moderate to severe plaque psoriasis (16-week CLARITY results). Dermatol Ther (Heidelb). 2018;8(4):571-579. doi:10.1007/s13555-018-0265-y
64. Bagel J, Blauvelt A, Nia J, et al. Secukinumab maintains superiority over ustekinumab in clearing skin and improving quality of life in patients with moderate to severe plaque psoriasis: 52-week results from a double-blind phase $3 \mathrm{~b}$ trial (CLARITY). J Eur Acad Dermatol Venereol. 2021;35(1):135-142. doi:10.1111/jdv.16558

65. Reich K, Armstrong AW, Langley RG, et al. Guselkumab versus secukinumab for the treatment of moderate-to-severe psoriasis (ECLIPSE): results from a phase 3, randomised controlled trial. Lancet. 2019;394(10201):831-839. doi:10.1016/S0140-6736(19) 31773-8

66. Warren RB, Blauvelt A, Poulin Y, et al. Efficacy and safety of risankizumab vs. secukinumab in patients with moderate-to-severe plaque psoriasis (IMMerge): results from a phase III, randomized, open-label, efficacy-assessor-blinded clinical trial. $\mathrm{Br} J$ Dermatol. 2021;184(1):50-59. doi:10.1111/bjd.19341

67. Bissonnette R, Luger T, Thaçi D, et al. Secukinumab demonstrates high sustained efficacy and a favourable safety profile in patients with moderate-to-severe psoriasis through 5 years of treatment (SCULPTURE Extension Study). J Eur Acad Dermatol Venereol. 2018;32(9):1507-1514. doi:10.1111/jdv.14878

68. Highlights of prescribing information: Siliq; April, 2020. Available from: https://www.bauschhealth.com/Portals/25/Pdf/PI/Siliq-pi.pdf. Accessed October 23, 2021.

69. Papp KA, Reich K, Paul C, et al. A prospective phase III, randomized, double-blind, placebo-controlled study of brodalumab in patients with moderate-to-severe plaque psoriasis. $\mathrm{Br} J$ Dermatol. 2016;175(2):273-286. doi:10.1111/bjd.14493

70. Lebwohl M, Strober B, Menter A, et al. Phase 3 studies comparing brodalumab with ustekinumab in psoriasis. $N$ Engl J Med. 2015;373 (14):1318-1328. doi:10.1056/NEJMoa1503824

71. Puig L, Lebwohl M, Bachelez H, Sobell J, Jacobson AA. Long-term efficacy and safety of brodalumab in the treatment of psoriasis: 120 -week results from the randomized, double-blind, placebo- and active comparator-controlled phase 3 AMAGINE-2 trial. J Am Acad Dermatol. 2020;82(2):352-359. doi:10.1016/j.jaad.2019.05.095

72. Lebwohl MG, Papp KA, Marangell LB, et al. Psychiatric adverse events during treatment with brodalumab: analysis of psoriasis clinical trials. J Am Acad Dermatol. 2018;78(1):81-89.e5. doi:10.1016/j. jaad.2017.08.024

73. Gordon KB, Foley P, Krueger JG, et al. Bimekizumab efficacy and safety in moderate to severe plaque psoriasis (BE READY): a multicentre, double-blind, placebo-controlled, randomised withdrawal phase 3 trial. Lancet. 2021;397(10273):475-486. doi:10.1016/ S0140-6736(21)00126-4

74. Reich K, Papp KA, Blauvelt A, et al. Bimekizumab versus ustekinumab for the treatment of moderate to severe plaque psoriasis (BE VIVID): efficacy and safety from a 52-week, multicentre, double-blind, active comparator and placebo controlled phase 3 trial. Lancet. 2021;397 (10273):487-498. doi:10.1016/S0140-6736(21)00125-2

75. Warren RB, Blauvelt A, Bagel J, et al. Bimekizumab versus adalimumab in plaque psoriasis. $N$ Engl J Med. 2021;385(2):130-141. doi:10.1056/NEJMoa2102388

76. Reich K, Warren RB, Lebwohl M, et al. Bimekizumab versus secukinumab in plaque psoriasis. $N$ Engl J Med. 2021;385(2):142-152. doi:10.1056/NEJMoa2102383

77. Ramirez-Carrozzi V, Sambandam A, Luis E, et al. IL-17C regulates the innate immune function of epithelial cells in an autocrine manner. Nat Immunol. 2011;12(12):1159-1166. doi:10.1038/ni.2156

78. Xu M, Lu H, Lee Y-H, et al. An interleukin-25-mediated autoregulatory circuit in keratinocytes plays a pivotal role in psoriatic skin inflammation. Immunity. 2018;48(4):787-798.e4. doi:10.1016/j. immuni.2018.03.019

79. Borowczyk J, Buerger C, Tadjrischi N, et al. IL-17E (IL-25) and IL-17A differentially affect the functions of human keratinocytes. $J$ Invest Dermatol. 2020;140(7):1379-1389.e2. doi:10.1016/j.jid. 2019.12.013 


\section{Publish your work in this journal}

ImmunoTargets and Therapy is an international, peer-reviewed open access journal focusing on the immunological basis of diseases, potential targets for immune based therapy and treatment protocols employed to improve patient management. Basic immunology and physiology of the immune system in health, and disease will be also covered. In addition, the journal will focus on the impact of management

Submit your manuscript here: http://www.dovepress.com/immunotargets-and-therapy-journal programs and new therapeutic agents and protocols on patient perspectives such as quality of life, adherence and satisfaction. The manuscript management system is completely online and includes a very quick and fair peer-review system, which is all easy to use. Visit http://www.dovepress.com/testimonials.php to read real quotes from published authors. 